\title{
Doctor and Media
}

Md. Badruddoza * $^{*}$

${ }^{1}$ Editor-In-Cheif

Chattagram Maa-O-Shishu Hospital Medical College Journal Chittagong, Bangladesh.
${ }^{*}$ Correspondence to:

\section{Dr. Md. Badruddoza}

Professor of Pediatrics

Chattagram Maa-O-Shishu Hospital Medical College

Chittagong, Bangladesh.

Mobile : +88 01819318764

E-mail: badrud_doza@yahoo.com

www.banglajol.info/index.php/CMOSHMCJ
Recently we have faced 2 incidents in 2 private hospitals where media was heavily involved. In one incident a newborn admitted in a private hospital was reported in the media as missing, abducted and sold in exchange of money, but ultimately found to be an exchange mistakenly occured between 2 beds in the neonatal ward. Despite authority's clarification, the media made the incident so clumsy and confusing that repeated inquiry committee were formed to come to the conclusion. The second incident happened in a private hospital where a child of a journalist died out of complications of the acute illness from which he was suffering. But they took the matter to the media, inquiry committee was formed and found no fault on the part of doctors But they filed cases against the doctor, consultant and hospital administration. The fate of the case is still pending in the court. The conflict reflects the attitude of the media men towards doctor community.

There is other side of the story also. National dailies recently highlighted an invention by the Department of Physics of a private university headed by a teacher. The research led to optical identification of cancer cell from the blood. Shortly the invention will be patented and the test will be available commercially at a low price. But the good news seldom publish in papers and bad news get preferences. Sometimes the cheap news get multiplied to increase the publicity and to get financial benefit.

Media and Health are 2 wings of public service. Doctors are directly taking care of the health of people. Maintenance of a good health is a necessary precondition to maintain normal activity of an individual so that growth of a child is ensured, an adolescent can pursue his studies, the youth can participate in academic and physical activities in full vigour, an adult can earn his livelihood and an old can continue his life in peace. That's why health is given so much priority in developed countries. Best students come to study medicine, better salaries are set for the doctors, best health structures are developed, emergency services are available free and health insurance are well covered.

In our country, media is more focused on tiny lapses of the doctors, how to degrade and punish them rather than to focus on a sound development of the health system. There is no awareness campaign on different health needs on the media, they publish ads that endanger the health.There is no in-depth report on the health system, no report on the contribution of health institutions in Bangladesh, no suggestions on the solution of conflicts between patients and physician, no solution for movement of patients from Bangladesh to neighbouring countries, no analysis on lack of health system in our country, no calculation on the needed student: population ratio or doctor:patient ratio.

Media can play greater role than casual reporting and help to develop a quality health care system that is more welfare oriented and inclusive.

\section{DISCLOSURE}

The author declare no competing interest 